\title{
Laboratory Design Concepts for Effective Utilization of Resources and Obtaining Greater Efficacy
}

\author{
doi:10.3991/ijet.v5i3.1323 \\ Dr. A. Srinath \\ K. L. University, Vaddeswaram, Guntur Dt, Andhra Pradesh, India
}

\begin{abstract}
Laboratories are workplaces for the conduct of experimentation across disciplines and perform interdisciplinary scientific research. This work will summarize the key architectural, engineering, and operational, safety, and sustainability considerations for the design Laboratories.
\end{abstract}

The author recognizes that in the 21st century we are pushing project design teams to create research laboratories that are responsive to current and future needs, that encourage interaction among students as well as researchers from various disciplines, that help recruit and retain qualified scientists, and that facilitates partnerships and development.

Index Terms-Laboratories design, mechanical needs, electrical needs, economical aspects

\section{ARCHITECTURAL CONSIDERATIONS}

Over the past 30 years, architects, engineers, facility managers, and researchers have refined the design of typical wet and dry labs to a very high level. The following identifies the best solutions in designing a typical lab.

\section{A. Lab Planning Module}

The laboratory module is the key unit in any lab facility. When designed correctly, a lab module will fully coordinate all the architectural and engineering systems. A well-designed modular plan will provide the following benefits:

- Flexibility — "The lab module should encourage change" within the building. Research is changing all the time, and buildings must allow for reasonable change. Many private research companies make physical changes to an average of $25 \%$ of their labs each year. Most academic institutions annually change the layout of 5 to $10 \%$ of their labs, this is being noticed annually across the globe.

- Expansion-The use of lab planning modules allows the building to adapt easily to needed expansions or contractions without sacrificing facility and functionality.

A common laboratory module has a width of approximately $10 \mathrm{ft}$. 6 in. but will vary in depth from 20-30 ft. The depth is based on the size necessary for the lab and the cost-effectiveness of the structural system. The $10 \mathrm{ft} .6$ in. dimension is based on two rows of casework and equipment (each row $2 \mathrm{ft} .6$ in. deep) on each wall, a $5 \mathrm{ft}$. aisle, and 6 in. for the wall thickness that separates one lab

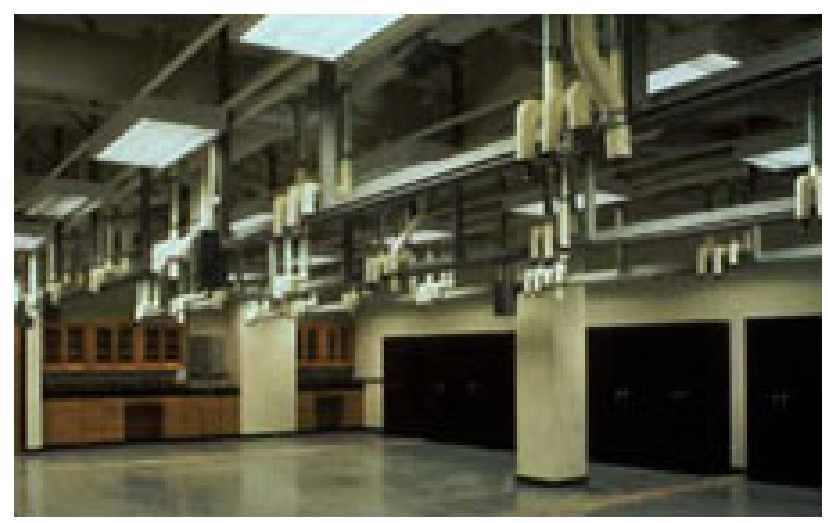

Figure 1. Building Attributes: Labs designed with overhead connects and disconnects allow for flexibility and fast hook up of equipment.

from another. The $5 \mathrm{ft}$. aisle width should be considered a minimum because of the requirements of the statutory norms of any Government Councils on Education and Technology which are as per the American standards generally.

Two-Directional Lab Module-Another level of flexibility can be achieved by designing a lab module that works in both directions. This allows the casework to be organized in either direction. This concept is more flexible than the basic lab module concept but may require more space. The use of a two-directional grid is beneficial to accommodate different lengths of run for casework. The casework may have to be moved to create a different type or size of workstation.

Three-Dimensional Lab Module-the threedimensional lab module planning concept combines the basic lab module or a two-directional lab module with any lab corridor arrangement for each floor of a building. This means that a three-dimensional lab module can have a single-corridor arrangement on one floor, a two-corridor layout on another, and so on. To create a threedimensional lab module:

- A basic or two-directional lab module must be defined.

- All vertical risers must be fully coordinated. (Vertical risers include fire stairs, elevators, restrooms, and shafts for utilities.)

- The mechanical, electrical, and plumbing systems must be coordinated in the ceiling to work with the multiple corridor arrangements. 


\section{B. Lab Planning Concepts}

The relationship of the labs, offices, and corridor will have a significant impact on the functioning and research outputs of any Institution.

- Do the end users want a view from their labs to the exterior, or will the labs be located on the interior, with wall space used for casework and equipment?

- Some researchers do not want or cannot have natural light in their research spaces. Special instruments and equipment, such as nuclear magnetic resonance (NMR) apparatus, electron microscopes, and lasers cannot function properly in natural light. Natural daylight is not desired in vivarium facilities or in some support spaces, so these are located in the interior of the building.

- Zoning the building between lab and non-lab spaces will reduce costs. Labs require $100 \%$ outside air while non-lab spaces can be designed with recirculated air, like an office building.

- Adjacencies with corridors can be organized with a single, two corridor (racetrack), or a three corridor scheme. There are number of variations to organize each type. Illustrated in Figures 2, 3 and 4 are three ways to organize a single corridor scheme.

- Open labs vs. closed labs. An increasing number of research institutions are creating "open" labs to support team-based work. The open lab concept is significantly different from that of the "closed" lab of the past, which was based on accommodating the individual principle investigator. In open labs, researchers share not only the space itself but also equipment, bench space, and support staff. The open lab format facilitates communication between scientists and makes the lab more easily adaptable for future needs. A wide variety of labs-from wet biology and chemistry labs, to engineering labs, to dry computer science facilities - are now being designed as open labs.

\section{Flexibility}

In today's lab, the ability to expand, reconfigure, and permit multiple uses has become a key concern. The following should be considered to achieve this:

1) Flexible Lab Interiors

- Equipment zones-These should be created in the initial design to accommodate equipment, fixed, or movable casework at a later date.

- Generic labs

- Mobile casework-This can be comprised of mobile tables and mobile base cabinets. It allows researchers to configure and fit out the lab based on their needs as opposed to adjusting to pre-determined fixed casework (see Figure 5).

- Flexible partitions-These can be taken down and put back up in another location, allowing lab spaces to be configured in a variety of sizes.

- Overhead service carriers-These are hung from the ceiling. They can have utilities like piping, electric, data, light fixtures, and snorkel exhausts. They afford maximum flexibility as services are lifted off the floor, allowing free floor space to be configured as needed.

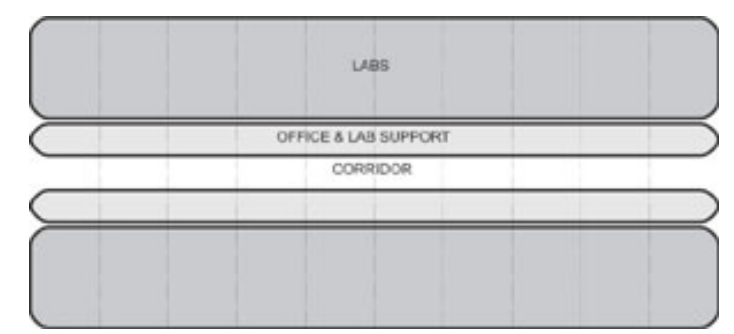

Figure 2. Single corridor lab design with labs and office adjacent to each other

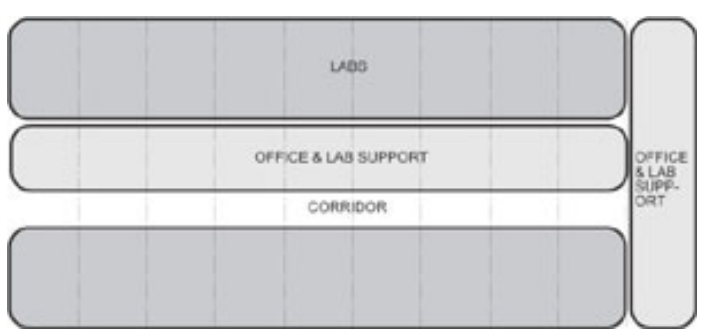

Figure 3. Single corridor lab design with offices clustered together at the end and in the middle

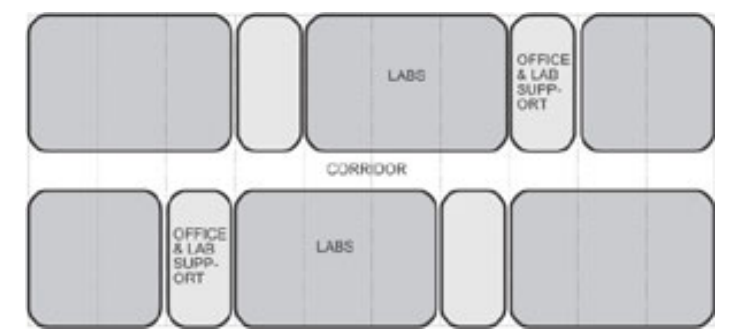

Figure 4. Single corridor lab design with office clusters accessing main labs directly

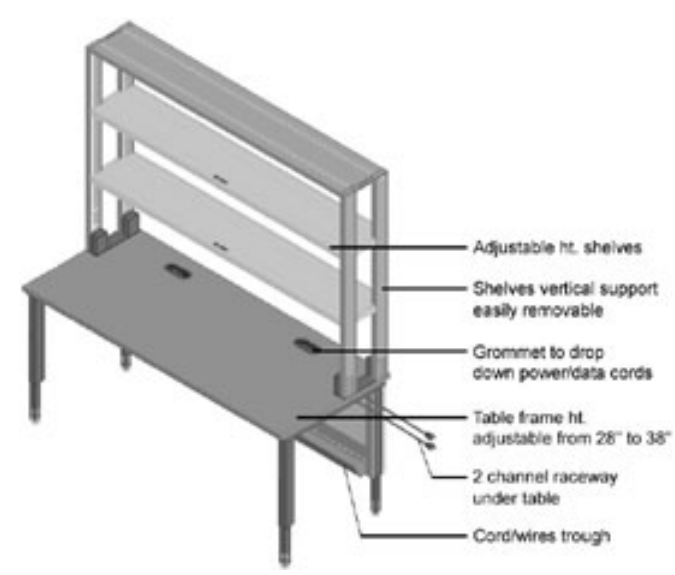

a)

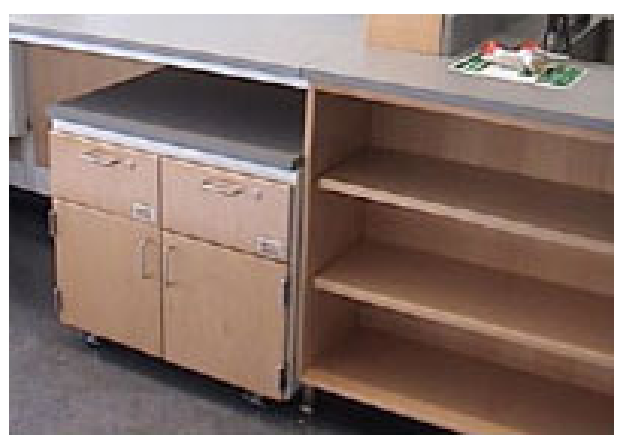

b)

Figure 5. Mobile casework (a) and mobile base cabinet (b) 
2) Flexible Engineering Systems

- Labs should have easy connects/disconnects at walls and ceilings to allow for fast and affordable hook up of equipment.

- The Engineering systems should be designed such that fume hoods can be added or removed.

- Space should be allowed in the utility corridors, ceilings, and vertical chases for future HVAC, plumbing, and electric needs.

\section{Mechanical Systems}

The location of main vertical supply/exhaust shafts as well as horizontal ductwork is very crucial in designing a flexible lab. Key issues to consider and include: efficiency and flexibility, modular design, less initial costs, longterm operational costs, building height and massing, and design image.

The various design options for the mechanical systems are illustrated in Figures 6 to 10.

\section{E. Electrical Systems}

Three types of power are generally used for most laboratory projects:

- Normal power circuits are connected to the utility supply only, without any backup system. Loads that are typically on normal power include some HVAC equipment, general lighting, and most lab equipment.

- Emergency power is created with generators that will back up equipment such as refrigerators, freezers, fume hoods, biological safety cabinets, emergency lighting, exhaust fans, animal facilities, and environmental rooms. Examples of safe and efficient emergency power equipment include distributed energy resources (DER), micro turbines, and fuel cells.

- An uninterruptible power supply (UPS) is used for data recording, certain computers, microprocessorcontrolled equipment, and possibly the vivarium area. The UPS can be either a central unit or a portable system, such as distributed energy resources (DER), micro turbines, fuel cells, and building integrated photo voltaic (BIPV).

The following should be considered:

- Load estimation

- Site distribution

- Power quality

- Management of electrical cable trays/panel boxes

- Lighting design

o User expectations

o Illumination levels

o Uniformity

o Lighting distribution-indirect, direct, combination

o Luminaire location and orientation-lighting parallel to casework and lighting perpendicular to casework

- Telephone and data systems

\section{o Piping Systems}

There are several key design goals to strive for in designing laboratory piping systems:

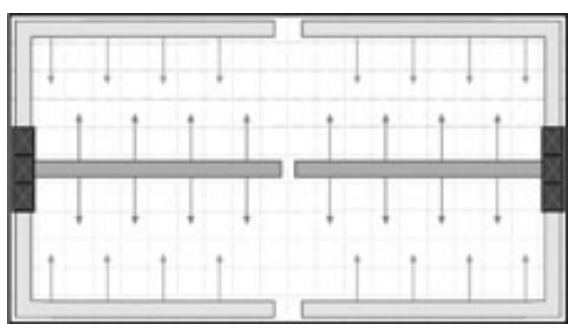

Figure 6. Shafts at the end of the building

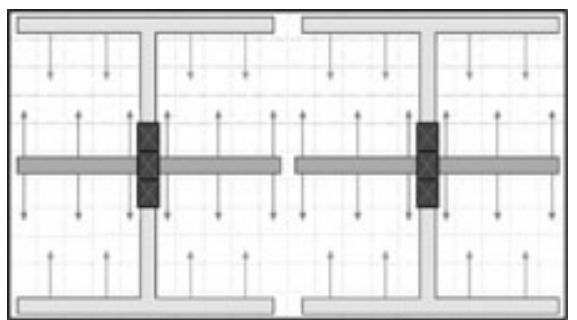

Figure 7. Shafts in the middle of the building

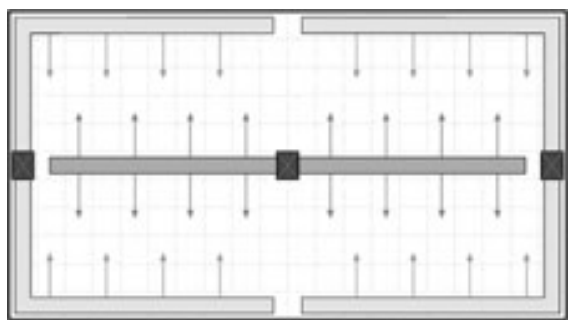

Figure 8. Exhaust at end and supply in the middle

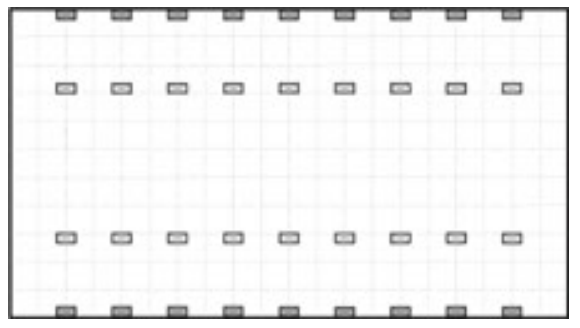

Figure 9. Multiple internal shafts

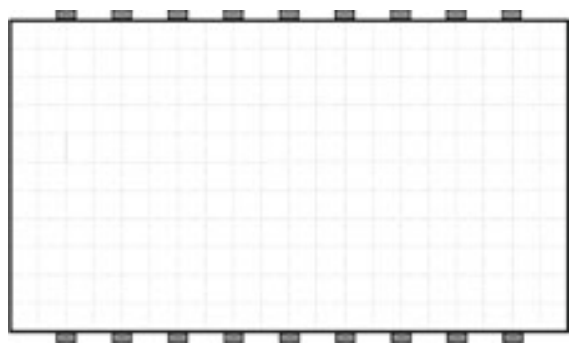

Figure 10. Shafts on the exterior

- Provide a flexible design that allows for easy renovation and modifications.

- Provide appropriate plumbing systems for each laboratory based on the lab programming.

- Provide systems that minimize energy usage.

- Provide equipment arrangements that minimize downtime in the event of a failure.

- Locate shutoff valves where they are accessible and easily understood.

- Accomplish all of the preceding goals within the construction budget. 


\section{OPERATIONS AND MAINTENANCE}

\section{A. Cost Savings}

The following cost saving items can be considered without compromising quality and flexibility:

- Separate lab and non-lab zones.

- Try to design with standard building components instead of customized components

- Identify at least three manufacturers of each material or piece of equipment specified to ensure competitive bidding for the work.

- Locate fume hoods on upper floors to minimize ductwork and the cost of moving air through the building.

- Evaluate whether process piping should be handled centrally or locally. In many cases it is more costeffective to locate gases, in cylinders, at the source in the lab instead of centrally.

- Create equipment zones to minimize the amount of casework necessary in the initial construction.

- Provide space for equipment (e.g., ice machine) that also can be shared with other labs in the entry alcove to the lab. Shared amenities can be more efficient and cost-effective.

- Consider designating instrument rooms as crosscorridors, saving space as well as encouraging researchers to share equipment.

- Design easy-to-maintain, energy-efficient building systems. Expose mechanical, plumbing, and electrical systems for easy maintenance access from the lab.

- Locate all mechanical equipment centrally, either on a lower level of the building or on the penthouse level.

- Stack vertical elements above each other without requiring transfers from floor to floor. Such elements include columns, stairs, mechanical closets, and restrooms.

\section{LAB AND PERSONNEL SAFETY AND SECURITY}

Protecting human health and life is paramount, and safety must always be the first concern in laboratory building design. Security-protecting a facility from unauthorized access - is also of critical importance. Today, research facility designers must work within the dense regulatory environment in order to create safe and productive lab spaces.

Laboratory classifications: dependent on the amount and type of chemicals in the lab;

- Containment devices: fume hoods and bio-safety cabinets;

- Levels of bio-safety containment as a design principle;

- Radiation safety;

- Employee safety: showers, eyewashes, other protective measures; and

- Emergency power.

\section{SUSTAINABILITY CONSIDERATIONS}

The typical laboratory uses far more energy and water per square foot than the typical office building due to intensive ventilation requirements and other health and safety concerns. Therefore, designers should strive to create sustainable, high performance, and low-energy laboratories that will:

- Minimize overall environmental impacts;

- Protect occupant safety; and

- Optimize whole building efficiency on a life-cycle basis.

\section{THREE LABORATORY SECTORS}

There are three research laboratory sectors. They are academic laboratories, government laboratories, and private sector laboratories.

- Academic labs are primarily teaching facilities but also include some research labs that engage in public interest or profit generating research.

- Government labs include those run by federal agencies and those operated by state government do research in the public interest.

- Design of labs for the private sector, run by corporations, is usually driven by the need to enhance the research operation's profit making potential.

\section{RELEVANT CODES AND STANDARDS}

The following agencies and organizations have developed codes and standards affecting the design of research laboratories. Note that the codes and standards are minimum requirements. Architects, engineers, and consultants should consider exceeding the applicable requirements whenever possible.

- 29 CFR 1910.1450: OSHA-Occupational Exposures to Hazardous Chemicals in Laboratories

- ISEA Z358.1-Emergency Eyewash and Shower Equipment

- ANSI/AIHA-American National Standard Z9.5 for Laboratory Ventilation

- Association for Assessment and Accreditation of Laboratory Animal Care (AAALAC) standards

- Department of Health and Human Services, Centers for Disease Control and Prevention and National Institutes of Health-Biosafety in Microbiological and Biomedical Laboratories, 4th Edition. 1999.

- Department of Veterans Affairs Research Laboratory Design Guide

- Facilities Standards for the Public Buildings Service, P100 by the General Services Administration (GSA).

- National Institutes of Health-NIH Design Policy and Guidelines

- National Institutes of Health (NIH)_Guidelines for the Laboratory Use of Chemical Carcinogens, Pub. No. 81-2385

- NFPA 30-Flammable and Combustible Liquids Code

- NFPA 45-Fire Protection for Laboratories using Chemical

- Tri-Services Unified Facilities Guide Specifications (UFGS)-UFGS, organized by MasterFormat ${ }^{\mathrm{TM}}$ divisions, are for use in specifying construction for the military services. Several UFGS exist for safetyrelated topics. 


\section{REFERENCES}

[1] Building Type Basics for Research Laboratories by Daniel Watch. New York, NY: John Wiley \& Sons, Inc., 2001. ISBN\# 0-47139236-7.

[2] CRC Handbook of Laboratory Safety, 4th ed. by A. K. Furr. Boca Raton, FL: CRC Press, 1995.

[3] Design and Planning of Research and Clinical Laboratory Facilities by Leonard Mayer. New York, NY: John Wiley \& Sons, Inc., 1995.

[4] Design for Research: Principals of Laboratory Architecture by Susan Braybrooke. New York, NY: John Wiley \& Sons, Inc., 1993.

[5] Guidelines for Laboratory Design: Health and Safety Considerations, 3rd Edition by Louis J. DiBerardinis, et al. New York, NY: John Wiley \& Sons, Inc., 2001.

[6] Guidelines for Planning and Design of Biomedical Research Laboratory Facilities by The American Institute of Architects, Center for Advanced Technology Facilities Design. Washington, DC: The American Institute of Architects, 1999.

[7] Handbook of Facilities Planning, Vol. 1: Laboratory Facilities by T. Ruys. New York, NY: Van Nostrand Reinhold, 1990.

[8] Laboratories, A Briefing and Design Guide by Walter Hain. London, UK: E \& FN Spon, 1995.

[9] Laboratory by Earl Walls Associates, May 2000.

[10] Laboratory Design from the Editors of R\&D Magazine.

[11] Laboratory Design, Construction, and Renovation: Participants, Process, and Product by National Research Council, Committee on Design, Construction, and Renovation of Laboratory Facilities. Washington, DC: National Academy Press, 2000.

[12] Planning Academic Research Facilities: A Guidebook by National Science Foundation. Washington, DC: National Science Foundation, 1992.

[13] Research and Development in Industry: 1995-96 by National Science Foundation, Division of Science Resources Studies. Arlington, VA: National Science Foundation, 1998.

[14] Science and Engineering Research Facilities at Colleges and Universities by National Science Foundation, Division of Science Resources Studies. Arlington, VA, most current version.

[15] Laboratories for the 21st Century (Labs21)—Sponsored by the U.S. Environmental Protection Agency and the U.S. Department of Energy, Labs21 is a voluntary program dedicated to improving the environmental performance of U.S. laboratories.

[16] http://www.wbdg.org

\section{AUTHOR}

Dr. A. Srinath is Professor at the Department of Mechanical Engineering and In charge Open Innovative Labs, K.L.University, Vaddeswaram 522502, Guntur Dt, Andhra Pradesh, INDIA, Phone: 0918645 246948, Fax: 0918645 247249, (srinath_me@klce.ac.in)

Manuscript received May $5^{\text {th }}, 2010$. Published as resubmitted by the author August $4^{\text {th }}, 2010$. 